\title{
A database of kinetic parameters for dissolution of selected primary and secondary minerals
}

MATYLDA HEŘMANSKÁ ${ }^{1}$, CHIARA MARIENI ${ }^{2}$, MARTIN VOIGT $^{3}$, JULIEN DECLERCQ ${ }^{4}$ AND ERIC H. OELKERS ${ }^{2}$

${ }^{1}$ Géosciences Environnement Toulouse-CNRS UMR 5563

${ }^{2}$ Géosciences Environnement Toulouse-CNRS

${ }^{3}$ Institute of Earth Sciences, University of Iceland

${ }^{4}$ SRK Consulting

Presenting Author: matylda.Hermanska@get.omp.eu

Mineral reactivity plays an essential role in many geochemical processes in the upper crust. Therefore, accounting for the kinetics of reactions is a crucial part of geochemical software such as PHREEQC or TOUGHREACT to interpret fluid-rock interactions at various $\mathrm{pH}$ and temperature conditions. However, the experimental dataset for mineral dissolution used for regression of kinetic parameters is often scattered due to, e.g., the effect of sample treatment or different experimental procedures between laboratories, or contain data at limited $\mathrm{pH}$ and temperature range.

To address this problem, we have created a kinetic database for the dissolution of selected major primary and secondary minerals. First, we have collected and evaluated the corresponding experimental datasets previously published in the literature. Then, the experimental dataset was regressed according to Equation (1). Each term in Equation (1) represents dissolution at acidic, neutral, and basic conditions, respectively. At the same time, $A$ is the pre-exponential factor, $E$ for apparent activation energy, $n$ is reaction order for a given mechanism, while $R$ is gas constant and $T$ temperature. In the case of the lack of experimental data, kinetic parameters were estimated from structural similarities within the same mineral group. Obtained kinetic equations were implemented into the carbfix.dat database, and they are available for direct use in the PHREEQC software and will be extended to other software as well. The kinetic database is applicable for $\mathrm{pH}$ from 2 to 12 and temperature up to $300^{\circ} \mathrm{C}$.

$$
r_{+}=\left(\left(A_{a} * \exp \left(\frac{-E_{a}}{R T}\right) *\left(a_{H^{+}}\right)^{n_{a}}\right)+\left(A_{b} * \exp \left(\frac{-E_{b}}{R T}\right)\right)+\left(A_{c} * \exp \left(\frac{-E_{C}}{R T}\right) *\left(a_{H^{+}}\right)^{-n_{c}}\right)\right) * S \quad \text { (1) }
$$

